\title{
Analysis on energy consumption in China
}

\author{
fuyue Chang, a) , qingcheng Wang*2, b) \\ ${ }^{1}$ school of Urban construction and security, shanghai institute of technology, shanghai 201418, china \\ ${ }^{2}$ school of Urban construction and security, shanghai institute of technology, shanghai 201418, china \\ a)976040171@qq.com \\ b) corresponding author wangqc@sit.edu.cn
}

\begin{abstract}
According to the China energy consumption situation between 2005to 2014 years, in accordance with the present conditions and the energy security strategy, the Shannon Wiener index of biodiversity research method and the Pielou evenness index of energy consumption in China has benn adopted., Research methods are employed to improve the diversity and balance of energy consumption, improve energy consumption safety, improve the security of energy use.
\end{abstract}

Keywords: energy consumption; Shannon Wiener diversity index; Pielou equilibrium index; energy security

\section{INTRODUCTION}

Traditional energy security refers to the availability of affordable prices to obtain adequate energy supply. As an important aspect of energy security, energy supply security and energy consumption security is particularly important. China's energy security situation is not optimistic, largely due to irrational energy consumption structure. Due to the influence of national conditions, energy security have been understanded differently in different countries. Foreign scholars on the issue of energy security is mainly aimed at the actual situation of the country, focusing on the protection of national security and the overall interests of the country. Domestic scholars focus on the research of energy supply security, and pay less attention to the rational use and sustainable development of energy, especially on the diversity of own energy consumption. Based on the study of domestic energy consumption, it will be analyzed the causes of the current energy consumption structure in this paper,which puts forward the methods and measures to improve the diversity of energy consumption, improve the safety of energy consumption, and ensure energy security. It is significent to evaluate the energy diversity and equilibrium degree of energy consumption in China in the past ten years (2005-2014). 


\section{RESEARCH METHODOLOGY}

The diversity index is used to describe the diversity of a community collectively measuring the ecology found in the beginning, it was used to describe the ecosystem biodiversity, distribution in economics can also be used to describe the area of economic activity. Diversity index is used to reflect species richness and equilibrium index. In the energy field, it mainly reflects the abundance of energy and the degree of energy balance.The Shannon Wiener index in terms of energy is often applied in the calculation and analysis of Chinese in recent ten years, the energy consumption diversity level, and Pielou evenness index, the level of understanding of energy security.

\subsection{Shannon Wiener index}

Step 1:p for a specific object system $\mathrm{R}$, the number of $\mathrm{E}$ per individual, thus determining the total amount of the system P;

$$
\mathrm{P}=-\sum_{i=1}^{R} e_{i}
$$

Step 2: calculate the relative contribution of each individual to the consumer system Pi;

$$
\mathrm{Pi}=\frac{e_{i}}{P}
$$

Step 3: the diversity index is the weighted geometric mean of each individual contribution (the higher the value, the higher the level of diversity).

$$
\mathrm{D}=-\sum_{i=1}^{R} p_{i} \times \ln p_{i}
$$

Shannon Wiener index can be used to determine the diversity of energy consumption, the energy consumption value depends on the type of input and uniformity. A system with only one energy consumption, its diversity is 0 (the smallest possible value). When the system has at least one energy consumption, and each energy consumption is uniform or equal, the diversity index reaches the maximum.

2.2 Pielou equilibrium index

The degree of equilibrium is used to describe the relative richness or proportion of individuals in the system. The Pielou equilibrium is usually expressed in terms of $\mathrm{E}$ :

$$
E=D / D_{\max }
$$

Among them: $\mathrm{D}$ is the actual observed diversity index, Dmax is the maximum diversity index (i.e., the diversity index of the maximum equilibrium), $D m a x=\ln R(R)$ is the total number of entities in the system. Equilibrium is the index of energy consumption. It is usually expressed by the actual diversity index and the comparison value of the maximum value.

3 research on energy consumption in China in recent ten years

In 1990s, China's economic society entered the stage of sustained and rapid development, but the rapid development of the environment caused a series of social problems: energy consumption, extensive economic development mode of high input, high consumption, low output. This pattern continues until now. At present, Coal, oil, natural gas, electricity and nuclear energy are the major consumption energy sources in China. Taking heavy industry as the leading factor is the main industry development mode of our country since twenty-first Century . As China's coal reserves are abundant, 
the coal resources are being exploited rapidly, which is the main energy source of our country. Oil, natural gas and other energy sources also occupy second of China's energy consumption. Wind power, hydropower and nuclear energy have a lower proportion of energy consumption in China, and these clean energy development potentials are much larger than those of coal, oil and natural gas.

So far, there is still a big gap between China's energy consumption structure dominated by coal and the energy consumption structure dominated by oil in the world. However, from the overall development trend, China's energy consumption structure is consistent with the world's energy consumption structure. As China's new energy and clean energy, coal and oil in the leading position in energy consumption will decline, the proportion of consumption of clean natural gas, nuclear energy, solar energy lamp will be a huge upgrade.

According to the China Energy Statistical Yearbook is the data from 2005 to 2014, the annual energy consumption (the use of coal consumption calculation method) as shown in Table 1.

TABLE 1. Composition of China's total energy consumption in 2005-2014

\begin{tabular}{cccccc}
\hline The year & $\begin{array}{c}\text { Total coal } \\
\text { consumption }\end{array}$ & $\begin{array}{c}\text { Total oil } \\
\text { consumption }\end{array}$ & $\begin{array}{c}\text { Total natural } \\
\text { gas consumption }\end{array}$ & $\begin{array}{c}\text { Total electricity } \\
\text { consumption }\end{array}$ & $\begin{array}{c}\text { Total energy } \\
\text { consumption }\end{array}$ \\
\hline 2005 & 189231.156 & 46523.682 & 6272.856 & 19341.306 & 261369 \\
2006 & 207402.108 & 50131.725 & 7734.609 & 21198.558 & 286467 \\
2007 & 225795.45 & 52945.14 & 9343.26 & 23358.15 & 311442 \\
2008 & 229236.865 & 53542.037 & 10900.774 & 26931.324 & 320611 \\
2009 & 240666.216 & 55124.664 & 11764.41 & 28570.71 & 336126 \\
2010 & 249568.416 & 62752.752 & 14425.92 & 33900.912 & 360648 \\
2011 & 271704.186 & 65023.224 & 17803.978 & 32511.612 & 387043 \\
2012 & 275464.53 & 68363.46 & 19302.624 & 39007.386 & 402138 \\
2013 & 280999.362 & 71292.123 & 22096.389 & 42525.126 & 416913 \\
2014 & 279328.736 & 74090.244 & 24270.942 & 48116.078 & 425806 \\
\hline
\end{tabular}

Note: the unit is $\mathbf{1 0 0 0 0}$ tons of standard coal.

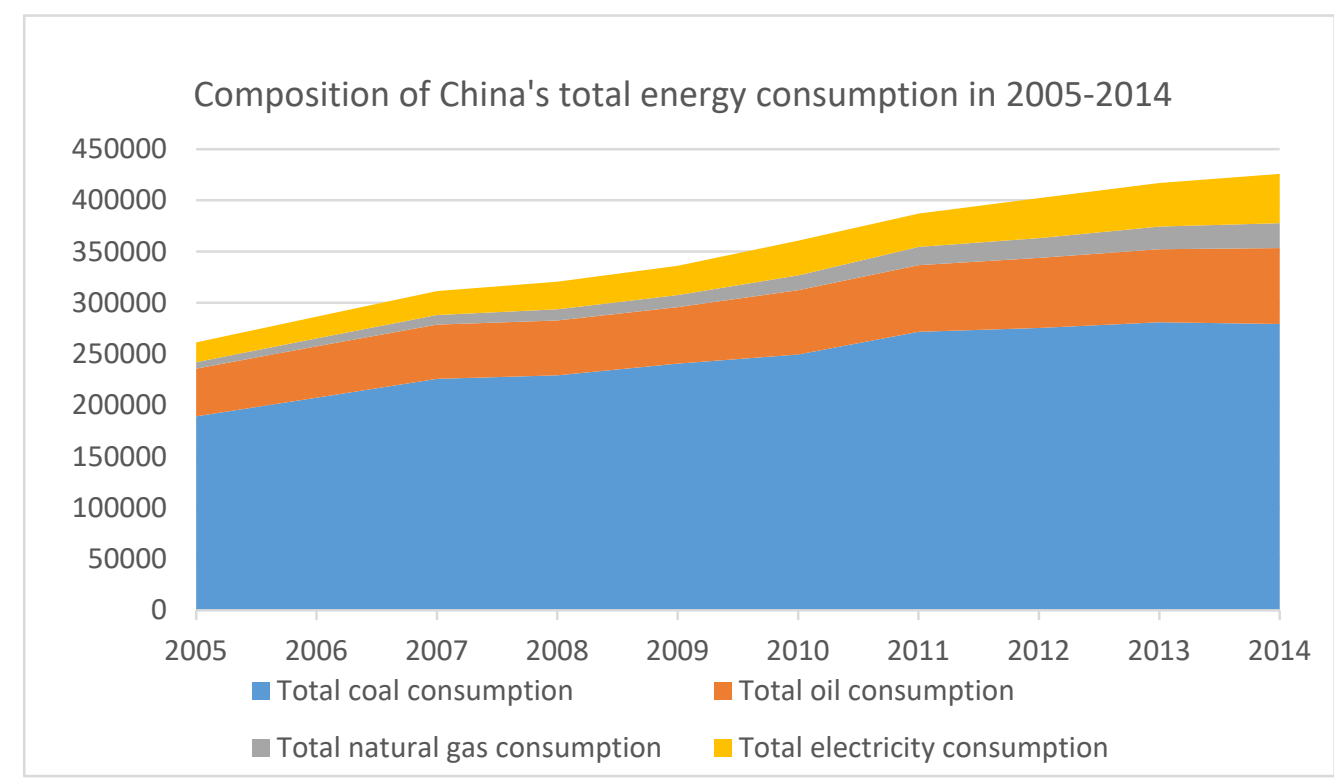

FIGURE 1 .2005-2014 The situation of energy consumption change Chinese. 
From table 1 and figure 1 shows: China's total energy consumption increased from 261 million 690 thousand tons of standard coal in 2005 to 4 billion 258 million 60 thousand tons of standard coal, coal consumption increased by 1 billion 892 million 310 thousand tons of standard coal in 2005 to 2 billion 793 million 280 thousand tons of standard coal in 2014, the average annual growth rate of 4.76\%; oil consumption increased by 465 million 320 thousand tons of standard coal in 2005 to 740 million 900 thousand tons of standard coal in 2014, the average annual growth rate of 5.9\%; the average annual growth rate of consumption of natural gas is $28.69 \%$, the average annual growth rate of electricity consumption was $14.9 \%$. It can be seen that in the past ten years, China's energy consumption continues to increase, coal consumption is still growing, but the growth rate is significantly lower than the growth rate of oil and gas and other energy. The development of electric power, such as nuclear power and hydropower, is also considerable, which plays an important role in improving the diversity of energy consumption in China, and plays an important role in improving energy security in china.

2.2 the relative contribution of each individual calculated Pi is shown in table 2:

TABLE 2. The relative contribution of each individual in China's energy consumption diversity 2005-2014 Pi

\begin{tabular}{ccccc} 
The year & Coal proportion & Oil proportion & Natural gas gravity & $\begin{array}{c}\text { The proportion of } \\
\text { electricity }\end{array}$ \\
\hline 2005 & 72.4 & 17.8 & 2.4 & 7.4 \\
2006 & 72.4 & 17.5 & 2.7 & 7.4 \\
2007 & 72.5 & 17 & 3 & 7.5 \\
2008 & 71.5 & 16.7 & 3.4 & 8.4 \\
2009 & 71.6 & 16.4 & 3.5 & 8.5 \\
2010 & 69.2 & 17.4 & 4 & 9.4 \\
2011 & 70.2 & 16.8 & 4.6 & 8.4 \\
2012 & 68.5 & 17 & 4.8 & 9.7 \\
2013 & 67.4 & 17.1 & 5.3 & 10.2 \\
2014 & 65.6 & 17.4 & 5.7 & 11.3 \\
\hline
\end{tabular}

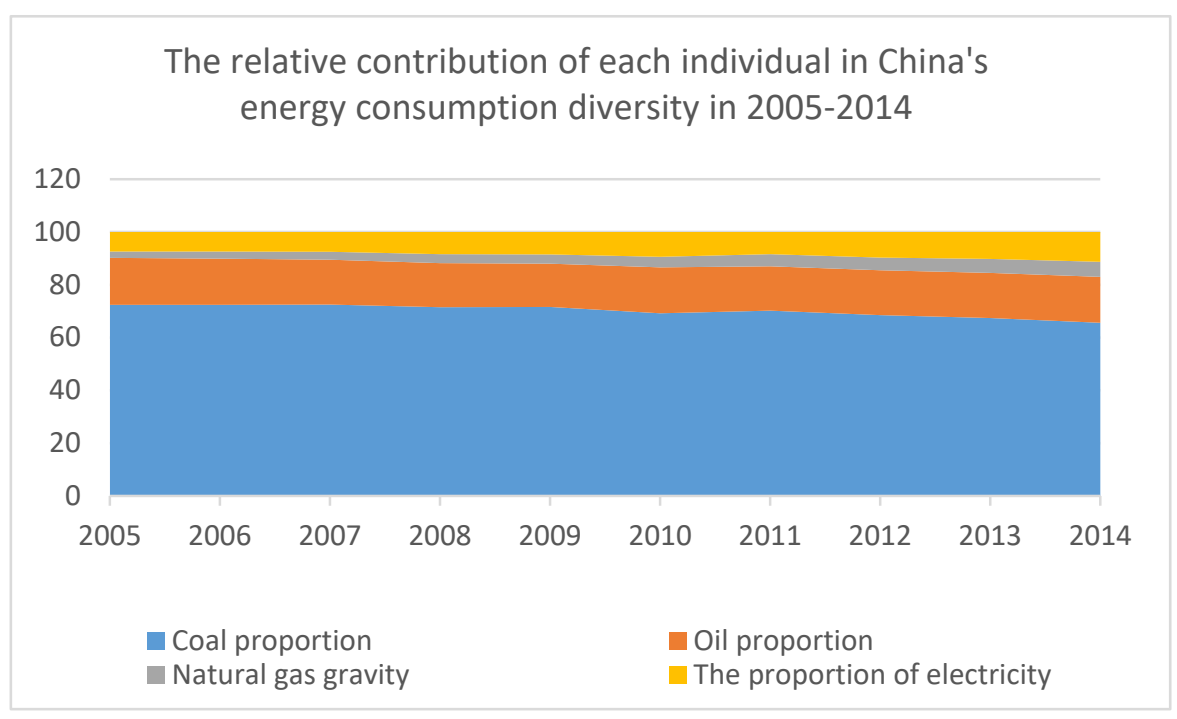

FIGURE 2 .The relative contribution of each individual in China's energy consumption diversity in 2005-2014 
From table 2 and Figure 2 Chinese energy consumption diversity of each individual the relative contribution of changes in the relative contribution of individual coal in 2005 72.4\% reduced to 65.6\%. the relative contribution of individual oil in 2014 has remained at around 17\%, the individual contribution of $24 \%$ natural gas increased to $5.7 \%$, relative contribution of individual power increased from $7.4 \%$ to $11.3 \%$. In the past ten years, the proportion of coal consumption has been reduced, the proportion of oil consumption has remained stable, and the proportion of natural gas and electricity consumption has been expanding. The rise in the proportion of electricity and natural gas is actually the result of China's sustainable development, the use of clean and efficient energy is an important step in China's sustainable development strategy. The use of electricity is mainly in the rapid development of nuclear power, hydropower and solar energy in China, which is clean and efficient, but there are still security, environmental conditions and technical defects.

TABLE 3. 2005-2014 China's energy consumption diversity parameters E and equilibrium index D

\begin{tabular}{|c|c|c|c|c|c|c|}
\hline The year & Coal proportion & Oil proportion & $\begin{array}{c}\text { Natural gas } \\
\text { gravity }\end{array}$ & $\begin{array}{l}\text { The proportion of } \\
\text { electricity }\end{array}$ & $\begin{array}{c}\text { Energy consumption } \\
\text { diversity D }\end{array}$ & $\begin{array}{c}\text { Equilibrium index } \\
\text { E }\end{array}$ \\
\hline 2005 & 72.4 & 17.8 & 2.4 & 7.4 & 0.8232 & 0.5938 \\
\hline 2006 & 72.4 & 17.5 & 2.7 & 7.4 & 0.829 & 0.5980 \\
\hline 2007 & 72.5 & 17 & 3 & 7.5 & 0.8338 & 0.6015 \\
\hline 2008 & 71.5 & 16.7 & 3.4 & 8.4 & 0.8619 & 0.6217 \\
\hline 2009 & 71.6 & 16.4 & 3.5 & 8.5 & 0.8625 & 0.6222 \\
\hline 2010 & 69.2 & 17.4 & 4 & 9.4 & 0.923 & 0.6658 \\
\hline 2011 & 70.2 & 16.8 & 4.6 & 8.4 & 0.8978 & 0.6476 \\
\hline 2012 & 68.5 & 17 & 4.8 & 9.7 & 0.9325 & 0.6727 \\
\hline 2013 & 67.4 & 17.1 & 5.3 & 10.2 & 0.9564 & 0.6899 \\
\hline 2014 & 65.6 & 17.4 & 5.7 & 11.3 & 1.1356 & 0.8192 \\
\hline
\end{tabular}

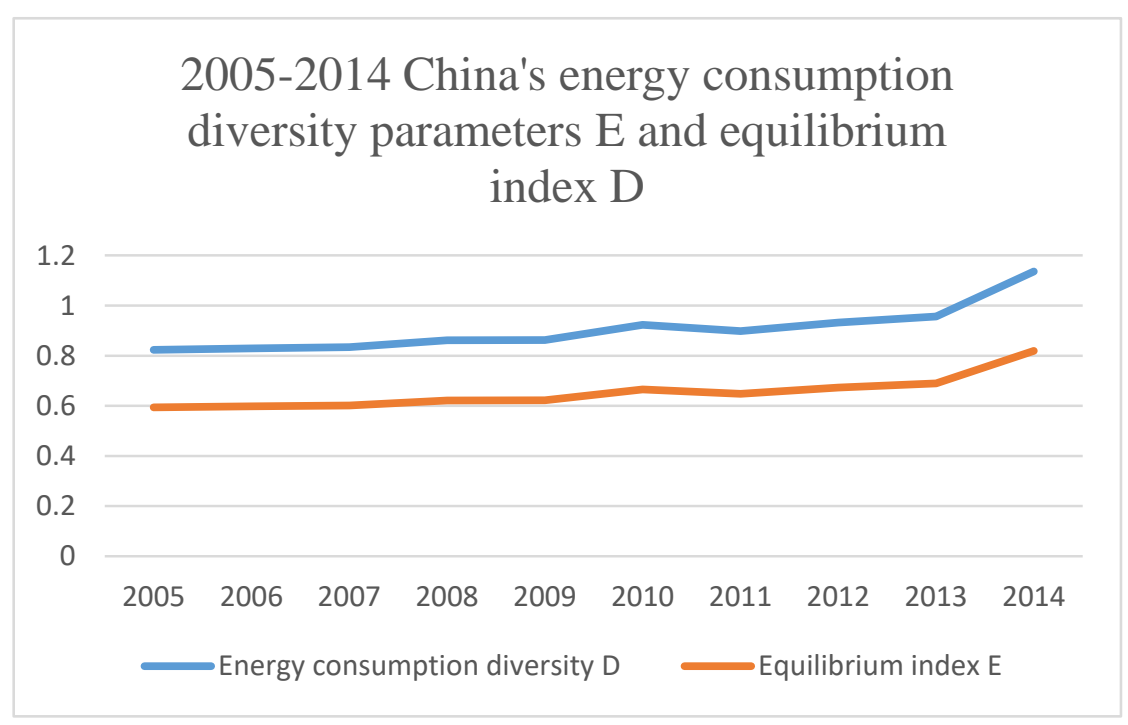

FIGURE 3. 2005-2014 China's energy consumption diversity parameters $E$ and equilibrium index D.

As shown in Table 3 and figure 3: data reflects China's overall energy consumption diversity is not very high, fluctuating between 0.8-1.1, evenness index fluctuation before $0.5-0.8$, the main reasons for this situation is China's major energy and coal accounted for a great proportion of the whole body, caused the diversity and equilibrium degree is not high, and with the industry of our country, the 
transformation and upgrading of enterprises, petroleum, natural gas and other clean energy development and utilization of the US energy consumption structure has been improved, which appeared diversity and evenness index is constantly increasing, also means that China's energy security is increasing.

\section{CONCLUSIONS AND RECOMMENDATIONS}

China's energy security is analyzed from the energy consumption situation and diversity index and equilibrium index of China in the past ten years (2005 -2014). Judging from the whole country, the main part of China's energy consumption is coal, which accounts for about $70 \%$ of the total energy consumption. This kind of consumption structure has poor diversity, low degree of balance, great environmental pollution, and is not suitable for sustainable development. However, with the development and utilization of new energy sources, the proportion of consumption of natural gas and clean energy is gradually increasing. At the same time, China is also actively foreign energy cooperation, will further expand the level and types of energy consumption. Overall, at present, China's energy consumption is high, but the diversity of energy consumption, the balance index is low, a good development trend but the energy consumption structure, the diversity of energy consumption is low, the difference of phase equilibrium degree.

For China's energy consumption, the following three suggestions:

1, improve energy efficiency. With the development of economy and the increasing of population, energy consumption increasing, energy efficiency does not solve the problem, whether it is the future of environmental problems and energy security can not carry, so improving energy efficiency is imperative.

2, vigorously develop clean energy and new energy. Vigorously develop hydropower, nuclear power, wind energy, such as high efficiency and pollution-free clean energy to a large extent, increase the diversity and balance of energy consumption in China, improve China's energy security and environmental pollution problems.

3 , change the energy consumption structure. The coal based energy consumption patterns to clean energy consumption patterns to change.

\section{REFERENCES}

1 Wang Xiaoqin, Yu Jing. New dimension of energy security measurement. Energy diversity, [J]., land and resources science and technology management,.2016 (1): 24-30.

2 Shanghai Statistics Bureau. Shanghai energy and environment statistics yearbook, 2016 Edition

3 Ju Ju Yi, Zhou Dequn, et al. Empirical analysis of the relationship between China's energy consumption structure and energy security [J]. resources science,.2010,32 (9): 1692-1697.

4 Wang Qiang, Chen Aijiao. Energy security assessment and characteristic analysis in Fujian province. [J]. Journal of Fujian Normal University,.2016.

5 Sizheng, Huang Dongfeng [J] in Zhejiang province. Research on sustainable development of energy. The index of energy engineering.2007 (2): 1-6

6 Zhao Yanna, Sun Yuqiang. Preliminary study on the construction of early warning index system for energy security in China [J]. ecology and economy: Academic Edition, 2010 (1): 63-66.

7 Qin Wen Zhan. Dynamic analysis of energy consumption and economic growth taking China's regions as an example [J]. Chinese business theory,.2016, (13): 174-177. 
8 Yin Jiahui. Study on the impact of energy consumption on energy security in China [J]. Tianjin Business University.2014.

9 Zhang Zhang. The current situation of energy consumption in China and the impact on energy security [J]. China Forum of Party and government cadres, 2012 (7): 18-20.

10 Bing Hua Lin, Hu Debao, Xing Wanli. Our city for the impact of energy consumption on [J]. Chinese mining, 2014 (6): 37-43. 